\title{
Mechanical Properties and Fracture Behavior of High-Strength Steels
}

\author{
R. Mušálek, ${ }^{1, a}$ P. Haušild, ${ }^{1, b}$ J. Siegl, ${ }^{1, c}$ J. Bensch, ${ }^{1, d}$ and J. Sláma ${ }^{2, e}$ \\ ${ }^{1}$ Czech Technical University, Faculty of Nuclear Sciences and Physical Engineering, Department of \\ Materials, Prague, Czech Republic \\ ${ }^{2}$ TKZ, ŠKODA AUTO a.s., Mlada Boleslav, Czech Republic \\ ${ }^{a}$ radek.musalek@fjfi.cvut.cz, ${ }^{b}$ hausild@fjfi.cvut.cz, ${ }^{c}$ jan.siegl@fjfi.cvut.cz, \\ ${ }^{\mathrm{d}}$ jan.bensch@fjfi.cvut.cz, ${ }^{\mathrm{e}}$ jan.slama@skoda-auto.cz
}

Typical thicknesses of high-strength steels (HSS) sheets used in the car industry are inapplicable for standardized testing procedures. The aim of this study is to propose an appropriate methodology for testing and comparing of thin HSS sheets. Microstructures were observed by means of light and scanning electron microscopy. The modified Charpy impact tests and fracture toughness tests were used in order to compare the fracture properties of three different HSS sheets (Docol $1200 \mathrm{M}$, Multiphase 1200 and BTR 165). Ductile-to-brittle transition curves and tearing resistance $(J-\Delta a)$ curves were measured. From the fracture toughness linked to the specimen thicknesses the value of fracture toughness $K_{I C}$ was estimated. Fractographic analysis of broken specimens has revealed that due to the fine microstructure of mixed ferrite-martensite fracture mechanism remains ductile even at low temperatures (down to $-100^{\circ} \mathrm{C}$ ).

Keywords: fracture toughness, Charpy impact energy, fractography, high-strength steel.

Introduction. High-strength steels are widely used in automobile industry for the reinforcement parts, e.g., door or b-pillar reinforcement. Their high strength makes it possible to use smaller cross sections, which leads to the reduction of car weight and, thus, of fuel consumption. Dues to extensive plastic deformation, high-strength steel parts are also able to absorb high impact energy during a crash, which improves car crew safety. Therefore the mechanical properties of these materials are of critical importance. So far, the standardized tests for the HSS sheets have not been designed. We propose a methodology for testing of thin HSS sheets by means of fracture mechanics and fractographic analysis.

Materials and Methods. Metallographic observation using light microscope (Neophot 32) and scanning electron microscope (JEOL JSM 5510LV) revealed fine ferritic-martensitic microstructures shown in Fig. 1. According to the observed microstructures and available tensile tests, it is concluded that due to thermomechanical treatment during the manufacturing process, rolling has relatively small influence on the isotropy of the observed materials.

The modified Charpy specimens for the impact toughness test [1] and the CT specimens for the fracture toughness test [2] were prepared from three high-strength steel sheets using a waterjet (for steel Docol $1200 \mathrm{M}$ ) and laser (Multiphase 1200 and BTR 165). All specimen dimensions corresponded to the standard [1, 2] except for the specimen thickness, which was equal to that of available steel sheets (Table 1).

The impact energy required to break the modified V-notched Charpy impact specimens into two pieces was measured using Charpy impact equipment with the maximum energy $150 \mathrm{~J}$. The specimens were cooled in the liquid nitrogen or mixture of liquid nitrogen and ethanol. The test temperature was measured by a thermocouple. The time interval between cooling and testing of the specimen was less than 5 seconds (usually 2 or 3 seconds).

Fracture toughness tests were conducted on CT specimens at room temperature using the Inova ZUZ 50 hydraulic loading machine. The testing procedure followed the 
ASTM 1820-99 [2] standard: a sharp fatigue crack was prepared, then the dependency of applied load vs. displacement was measured and the crack growth was studied using the light microscope.

Fractographic analysis using scanning electron microscope JEOL JSM-840A was carried out on the fracture surfaces of broken specimens.

$\mathrm{T}$ a b 1 e 1

Chemical Composition of Tested High-Strength Steels (wt.\%)

\begin{tabular}{|c|c|c|c|c|c|c|c|c|c|c|c|}
\hline Material & $\mathrm{C}$ & $\mathrm{Si}$ & $\mathrm{Mn}$ & $\mathrm{P}$ & $\mathrm{S}$ & $\mathrm{Cr}$ & $\mathrm{Mo}$ & $\mathrm{Al}$ & $\mathrm{Ti}$ & $\mathrm{B}$ & $\mathrm{Nb}$ \\
\hline $\begin{array}{c}\text { Docol } \\
1200 \mathrm{M}\end{array}$ & 0.12 & 0.20 & 1.60 & 0.015 & 0.002 & - & - & $\geq 0.03$ & - & - & 0.015 \\
\hline $\begin{array}{c}\text { Multiphase } \\
1200\end{array}$ & 0.13 & 0.12 & 1.30 & $\leq 0.020$ & $\leq 0.002$ & 0.25 & - & 0.03 & 0.05 & - & - \\
\hline BTR 165 & $0.19-$ & $\begin{array}{c}0.15- \\
0.25\end{array}$ & $\begin{array}{c}1.10- \\
1.40\end{array}$ & $\leq 0.025$ & $\leq 0.015$ & $\leq 0.35$ & $\leq 0.35$ & $\begin{array}{c}0.02- \\
0.06\end{array}$ & $\begin{array}{c}0.02- \\
0.05\end{array}$ & $\begin{array}{c}0.002- \\
0.005\end{array}$ & - \\
\hline
\end{tabular}
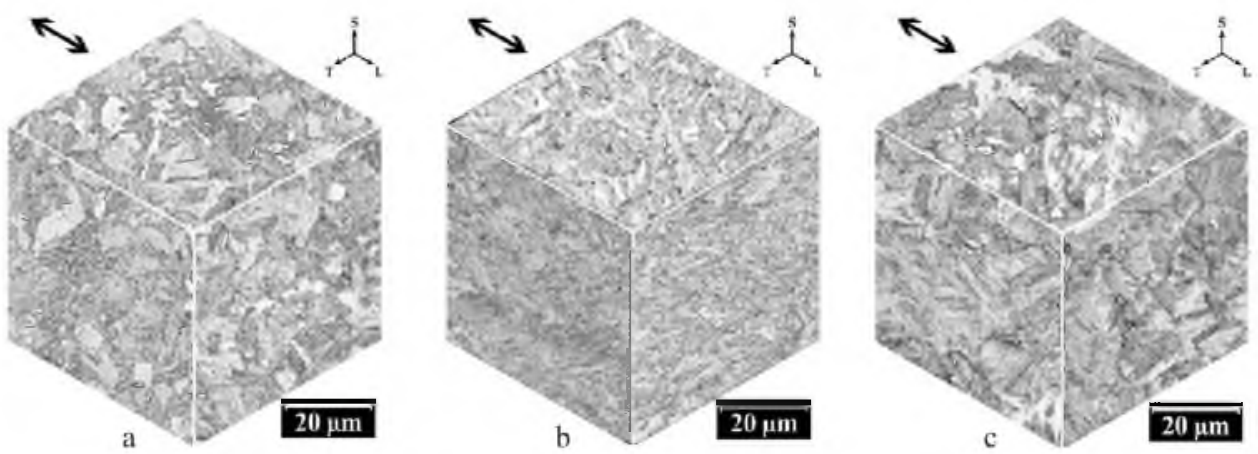

Fig. 1. Microstructure of tested steels: (a) Docol 1200 M, (b) Multiphase 1200, and (c) BTR 165.

Experimental Results and Discussion. The modified Charpy impact test has revealed ductile-to-brittle transition behavior of the high-strength steel sheets shown in Fig. 2. Ductile-to-brittle transition temperature was determined to be lower than $-100^{\circ} \mathrm{C}$. Due to the different thicknesses of tested sheets, the impact energy value was normalized by the specimen thickness to the impact toughness $K C V$. The highest value of the impact toughness above the transition temperature was observed for Docol $1200 \mathrm{M}$ steel.

Fracture toughness $K_{c}$ of the observed materials was determined (Table 2). Due to the small thicknesses $B$ of the tested materials, the plane strain condition was not satisfied, and the fracture toughness value had to be linked to the specimen thickness. However, the value of fracture toughness under plane strain condition $K_{\mathrm{I} c}$ can be estimated from formula [4]:

$$
K_{c}=K_{\mathrm{lc}} \sqrt{1+\frac{1.4}{B^{2}}\left(\frac{K_{\mathrm{I} c}}{R_{p 0.2}}\right)^{4}} .
$$

The load vs. displacement curve and known crack lengths can be used to evaluate the tearing resistance curves $(J-\Delta a)$ (see Fig. 3) according to the formula:

$$
J=\frac{2 A}{B(w-a)},
$$


where $A$ is the area under the load vs. displacement curve, $B$ is the specimen thickness, $w$ is specimen width, and $a$ is crack length.

These curves give some idea about the resistance of the material against ductile tearing. The steeper curve corresponds to the higher resistance. From these curves it can be observed that Docol $1200 \mathrm{M}$ and Multiphase 1200 have a very similar tearing resistance. Lower resistance of the BTR 165 steel can be due to the smaller thickness of this sheet and the higher influence of shear mode III on crack propagation.

$\mathrm{T}$ a b 1 e 2

Measured Values of Fracture Toughness

\begin{tabular}{|c|c|c|c|c|}
\hline Material & $\begin{array}{c}B, \\
\mathrm{~mm}\end{array}$ & $\begin{array}{c}R_{p 0.2}, \\
\mathrm{MPa}\end{array}$ & $\begin{array}{c}K_{c}, \\
\mathrm{MPa} \cdot \mathrm{m}^{1 / 2}\end{array}$ & $\begin{array}{c}K_{\mathrm{I} c}, \\
\mathrm{MPa} \cdot \mathrm{m}^{1 / 2} \\
(\text { estimate) }\end{array}$ \\
\hline Docol 1200 M & 2.0 & 1061 & 107.95 & 56.00 \\
\hline Multiphase 1200 & 2.0 & 1061 & 115.34 & 57.51 \\
\hline \multirow{2}{*}{ BTR 165 } & 2.0 & 1148 & 136.04 & 64.39 \\
& 2.0 & 1148 & 122.51 & 61.77 \\
& 1.0 & 1148 & 119.05 & 61.06 \\
\hline 1.5 & 1243 & 119.22 & 58.79 \\
& 1.5 & 1243 & 126.31 & 60.14 \\
\hline
\end{tabular}

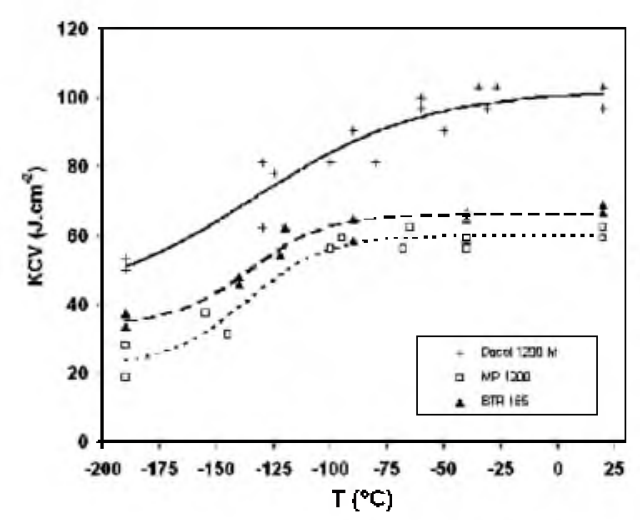

Fig. 2. Ductile-to-brittle transition curves.

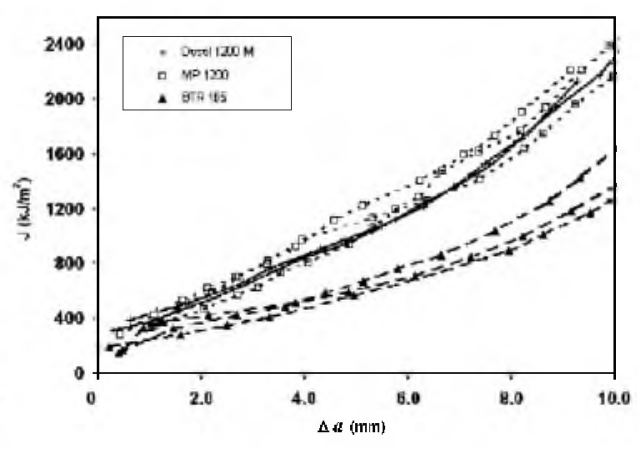

Fig. 3. Tearing resistance curves.

Fractographic analysis of broken Charpy specimens has confirmed that failure mechanisms of tested HSS sheets remain ductile even at a low temperature (down to $-100^{\circ} \mathrm{C}$ ). Due to the small thickness, shear lips were observed on fracture surfaces of all specimens tested above the transition temperature. Ductile dimples were observed on the whole fracture surface of specimens broken above the transition temperature. Below the transition temperature mostly features of cleavage fracture were observed (Fig. 4).

Fractographic analysis of broken CT specimens has shown that the crack was initiated at the tip of the fatigue pre-crack. In the first stage crack propagated in the mode I, and then, the crack propagated in the mixed mode I+III due to the small thickness and shear stress present in the material.

Ductile dimples stretched in the direction of crack growth were observed on some fracture surfaces of the specimens broken above the transition temperature (Fig. 5). 


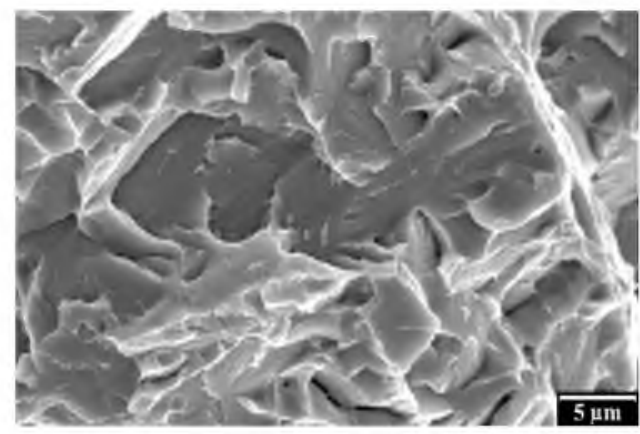

Fig. 4

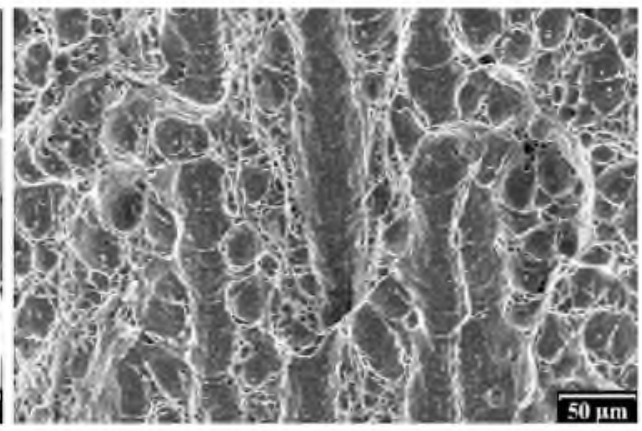

Fig. 5

Fig. 4. Typical morphology of Charpy specimen fracture surface broken below the transition temperature. (Docol $1200 \mathrm{M}$, test temperature $=-190^{\circ} \mathrm{C}$.)

Fig. 5. Typical morphology of Charpy specimen fracture surface broken above the transition temperature. (Docol $1200 \mathrm{M}$, test temperature $=20^{\circ} \mathrm{C}$.)

Conclusions. With respect to the slight differences in the specimen thickness of different materials, it has been found that from the point of view of fracture mechanics all the three observed high-strength steels have very similar mechanical properties.

The ductile-to-brittle transition temperature is beyond the typical high-strength steel application range The observed HSS sheets remained ductile even at a rather low temperature, which was proven by the fractographic analysis.

It has been confirmed that a new approach to the thin HSS sheets testing by the means of fracture mechanics is applicable and provides new information on the behavior of high-strength steel materials under the dynamic loading. The designed method is used for further material testing of HSS sheets.

Acknowledgments. The authors acknowledge the support from the SKODA AUTO, a.s. company. This project was supported by the Ministry of Education, Youth, and Sport of the Czech Republic in the frame of the project MSM 6840770021.

1. ĆN EN 10 045-1. Charpy Impact Test [in Czech], Český Normalizační Institut (1998).

2. ASTM Standard E 1820-99. Standard Test Method for Measurement of Fracture Toughness. Annual Book of ASTM Standards (1999), pp. 972-1005.

3. Y. J. Chao, Jr., J. D. Ward, and R. G. Sands, "Charpy impact energy, fracture toughness, and ductile-brittle transition temperature of dual phase 590 steel," Mater. Design, 28, 551-557 (2007).

4. G. R. Irwin, "Fracture transition for a crack traversing a plate," J. Basic Eng., 82, 417-425 (1960).

5. R. Mušálek, Special Materials Characteristic of High-Strength Sheet for Automotive Industry [in Czech], Master's Thesis, FNSPE, CTU Prague (2006). 